\title{
Talents, Competencies and Techniques of Business Analyst: A Balanced Professional Development Program
}

\author{
Anna Bobkowska \\ Faculty of Electronics, Telecommunications \\ and Informatics, Gdansk University of Technology \\ Narutowicza 11/12, 80-233 Gdańsk, Poland \\ Email: annab@eti.pg.gda.pl
}

\begin{abstract}
This paper presents preliminary results of action research in which we search for fundamentals of an universal theory of balanced approaches to software process. It is developed on the basis of balanced approach for professional development program for business analysts which integrates approaches oriented on talents, competencies and techniques. This paper includes the description of key concepts in background approaches, components of the framework for professional development program for business analysts and preliminary results of the universal theory of balanced approaches to software process.
\end{abstract}

\section{INTRODUCTION}

W HEN asking the question "Can everyone become a good business analyst?" during the trainings for students and professionals, nearly $100 \%$ of answers is "no". The role of business analysts in software projects becomes increasingly important and challenging [1-3]. Business analysts perform their tasks on the edge of several domains. They are expected to provide a link between business and technology. They should support managers in making decisions about innovations. The results of their performance have a large impact on the work of software developers and the final success or failure of software projects. Tasks of business analysts require huge knowledge, several behavioral skills, proper attitudes, and probably... real talents. Additionally, it seems that business analysts have to learn continuously and acquire diversified experience in order to deal with more and more advanced challenges. Thus, the problem of effective professional development program is important to individual business analysts who want to develop their career. Additionally, it is in scope of interest of coaches, mentors or tutors who can support business analysts in their professional development as well as project managers or human resources (HR) managers who are responsible for goal achievement in projects or organization capability.

Traditional approaches to education of system or business analysts are based on teaching several techniques, including requirements engineering, software modeling and business modeling. On the other hand, best practice rooted in industry emphasizes the importance of behavioral competencies, such as communication or interaction skills. Since they depend on personality features and they are difficult to assess by teachers, they often are skipped in education. Talent-oriented or career-oriented approaches are not popular in business analysis education, with a few exceptions [4-5]. The term of talent appears mainly in job offers for business analysts, but not much research has been done in this area. Approaches based on methodology, competencies and talents have different fundamental assumptions. Thus the following questions can be posed: Are these approaches contradictory or complementary? Is there another kind of relationship between them? How to integrate them? How to balance actions recommended by them? Could a universal theory of balanced approaches be helpful in performing these tasks?

The goals of the paper are:

- to present a balanced approach to professional development of business analysts which integrates talent-oriented approach, competence development and methodological software process definition,

- to search for fundamentals of an universal theory of balanced approaches to software process.

We apply the research methodology inspired by action research [6]. When solving a practical problem of supporting business analysts in their professional development, we attempt to find universal concepts of balanced approaches which can be useful also for solving the problems of balanced approaches in other contexts. In our argumentation, we use also other cases of balanced or integrated approaches.

The paper is structured as follows. Section 2 presents key concepts in the background approaches. Section 3 describes components of the framework for balanced approach to the program of professional development of business analysts. Section 4 presents preliminary results of searching for fundamentals of the universal theory of balanced approaches. Section 5 draws conclusions and presents prospects for further work.

\section{KEY CONCEPTS IN BACKGROUND APPROACHES}

The background approaches take different perspectives which is manifested by different terminology and patterns of action. In order to be precise in our considerations, we select a few characteristic approaches and mark their key concepts. We also attempt to make connection points between them with the purpose of preparation to a balanced approach.

The following background approaches are used:

- methodological approach represented by IBM Rational Unified Process (IBM RUP) which has defined a group 
of analysts roles in software development process and has assigned to them tasks and work products [7-9],

- competencies described in "A Guide to the Business Analysis Body of Knowledge (IIBA BABOK Guide) [2],

- talent-oriented approach $[10,11]$ which is based on recognition of personal talents and continuous development of professional competencies.

\section{A. Methods and Techniques}

IBM RUP defines roles in software development process. The group of analysts includes the following roles: business architect, business designer, businessprocess analyst, requirements specifier, stakeholder and system analyst. The roles have very precise descriptions. They are related to tasks and to work products for which the roles are responsible. A set or required skills is defined for each role. For example, "a person acting as business-process analyst must be a good facilitator and have excellent communication skills; knowledge of the business domain is essential for those acting in this role". Roles, tasks and work products are used in configurations of software process for given types of projects and they are used for preparing plans of software development for concrete projects. In context of company, analysts are expected to perform their tasks according to their role description in order to produce work products. They can use several kinds of guidelines. The main values are methodological rigor and efficient performance of high quality work products.

IBM RUP contains description of skills, which makes a connection point to competence-based approach. The detailed description of roles can be used for career path definition. However, when changing the company, a person can face other career paths. A set of methodological role definitions may direct individual program of competence development by indicating the skills which are important in a given professional situation.

\section{B. Business Analyst Competencies}

IIBA BABOK Guide defines a business analyst as "any person who performs business analysis tasks described in the $B A B O K ®$ Guide, no matter their job title or organizational role." For effective performance, business analysts should have competencies in the following groups:

- Analytical thinking and problems solving;

- Behavioral characteristics, such as ethics, trustworthiness, and personal organization;

- Business knowledge about general principles, industryspecific, organizational and knowledge about solutions;

- Communication skills;

- Interaction skills including facilitation and negotiation, leadership and teamwork; and

- Tools and technology.

Effectiveness measures are described for all competencies which allows for making assessments. The main value of this approach is in adaptability to the needs based on professional skills. Techniques in IIBA BABOK guide constitute a kind of toolbox.
The extensive description of underlying competencies makes a significant contribution of IIBA, but the IIBA BABOK Guide contains also methodological components such as knowledge areas, tasks in the knowledge areas and related techniques.

\section{Talent-Oriented Approach}

A popular way of thinking about changes in personal development is a transition from a present (AS-IS) state to the desired (TO-BE) state. When this approach is integrated with talent recognition, it might lead to perfection. The elements of the change can include the knowledge, the practical use of some techniques and the behavioral skills and attitudes.

Talent management is one of the trends in HR management nowadays. Talents are naturally recurring patterns of thought, feeling or behavior that can be productively applied to achieve a nearly-perfect performance of a given activity. The activity is performed with ease and pleasure. It gives satisfaction. On contrary, the lack of talent causes several difficulties and negative emotional attitudes when performing the activity. Talent management can be considered from both individual and organizational perspectives. There are several topics in debate about talents, including the percentage of talented employees in organization ranging from $2 \%$ to entire $100 \%$; the features which constitute talents; possible dependence on organizational context; and effective ways of talent management. It is believed that talent, passion and hard work are key factors of every success.

Talented individuals who want to become successful business analysts should individually elaborate vision of their careers and find ways of making progress by gaining experience and competence development. The connection point to methodologies is the following: talent development can be supported by taking a sequence of more and more challenging positions or roles. Explicit knowledge of required competencies can help in conscious improvement of their skills.

\section{BALANCING TALENTS, COMPETENCIES AND TeChNiQues In Professional DeVElopMent Program}

This section describes an attempt to integrate approaches based on talents, competencies and methodologies of business analysts in a framework for balanced professional development program.

\section{A. Framework Overview}

The main components of the framework are presented in Fig. 1. The fundamental element of professional development program is a change from assessment of present (AS-IS) state to the vision of desired ( $\mathrm{TO}-\mathrm{BE}$ ) state. Obviously not just one change, but several changes should be performed iteratively. For the first change, a pure self-assessment and a rough vision of the desired TO-BE state should be made. Starting from the second iteration, results of action from previous iterations can be used as criteria of assessment and progress evaluation. In further steps, effectiveness measures find their application. 


\begin{tabular}{|c|c|c|}
\hline $\begin{array}{l}\text { Assessment } \\
\text { of present } \\
\text { (AS-IS) state }\end{array}$ & $\begin{array}{c} \\
\text { Plan of actions in } \\
\text { professional }\end{array}$ & $\begin{array}{c}\text { Vision of } \\
\text { desired } \\
\text { (TO-BE } \\
\text { state }\end{array}$ \\
\hline & development & \\
\hline \multicolumn{3}{|c|}{$\begin{array}{l}\text { Resources: } \\
\text { Talents and career planning } \\
\text { Categories of business analyst competencies } \\
\text { Effectiveness measures for the competencies } \\
\text { Job requirements or role description } \\
\text { Techniques in software development process } \\
\text { Trends in business analysis or in related domains }\end{array}$} \\
\hline
\end{tabular}

Fig. 1. A framework for professional development program

The individual program includes also plan of actions on the way of making the change. It can be related to gaining new knowledge about principles of business, certain industry or organization. It can contain a task to learn a new business analysis technique or CASE tool features. The training can be achieved by self-studies or participating in specialized courses. In other cases, skills can be acquired by experience of performing certain kinds of activities. Probably, the most difficult to gain are the behavioral competencies, such as communication skills and interaction skills. However, with the progress in the area of personal development training and coaching, these kinds of change are also possible.

\section{B. Resources}

Both the vision of TO-BE state and the assessment of AS-IS state can be supported by resources which can constitute a frame of reference for making proper decisions.

The change can be based on recognition of talents and ambition of career development. In this case, one can start with their strengths, practice related activities and develop complementary skills which allow for solving more and more advanced problems.

The change can be driven by career path defined in a company. In this case, it starts with a list of job requirements or role description in software process (e.g. role definitions in companies which develop software according to IBM RUP). The training can facilitate further steps in career path. The job requirements can be also used as a checklist for selfassessment and serve as a basis for formulation of the vision of TO-BE state.

When specific job requirements are not available or skill development is made with a more general purpose, one can use more general frames of reference, such as categories of business analyst competencies in IIBA BABOK Guide. In this case, detailed effectiveness measures can be useful for tracing the progress.

For advanced business analysts, professional literature on business analysis trends or advances in business knowledge in related domains can be used in continuous professional development.

\section{Discussion}

When attempting to reflect on the framework from metaconceptual perspective, one can notice that the core concept of change has been taken from personal development perspective. This is because it is the most closely related to the problem to be solved. Other background approaches contribute to resources in an additive manner. It is good to see their unified role. But on the other hand, there are no recommendations how to balance use of resources in given circumstances. In order to capture this issue more precisely, some knowledge about general rules of balanced approaches would be useful.

This framework has been verified in a case study. It has shown usefulness of the terminology for description of real case and for directing iterative professional development program. Additionally, it highlighted aspects related to practical application, such as the role of coach in this process.

\section{TOWARDS A UNIVERSAL THEORY OF BALANCED APPROACHES}

\section{A. Universal Problem}

The concept of balanced approaches to software process has a much broader scope. Almost all software companies face the challenge of changes in the surrounding world which force them to adapt. They have usually worked out some effective software processes related to their expertise. On the other hand, new technologies and approaches are being proposed. How to keep their best practice and improve with new approaches? How to keep balance in this activity? The best example of common challenge which several companies had to face recently was the confrontation of methodological software development processes with the trend of agile approaches. Some companies had to deal also with increasing requirements regarding usability and user experience. Other trendy approaches include: business process management, collaborative software development, mobile application, gamification, smart technologies, idea of cashless world, etc. One can expect, that novel approaches are being continuously proposed in future. In consequence, software companies will have to address the challenges of innovation and adaptation continuously. Can we facilitate it with an universal theory of balanced approaches?

\section{B. From Balanced Program to Universal Theory}

Having the results of balanced professional development program with a case study of its application in practice, we are going to see how it can contribute to a unified theory of balanced approaches. The second question is whether they are general or not.

We have started with key concepts of approaches to be balanced and we were looking for connection points. The problem of balancing any approaches is not about providing solutions from scratch. It is always based on some background approaches. Furthermore, we need to integrate them before we can balance them. 
Several strategies were used in order to integrate and balance the approaches. Selection of the core approach of change in professional development program and collecting resources from all background approaches in an additive manner to form a frame of reference were performed at the stage of building the framework. Selection of the first-need skill, best-fit techniques, or continuous grow strategies were used in practical application. It seems they were chosen based on changing circumstances. Factors considered for background approaches included: motivation, terminology, context of discovery, strengths and weaknesses. Thus, there is not just one proper way of balancing several approaches. In general, the diversity of possible ways how to integrate and balance can be captured by patterns.

The case study has shown that not all aspects of practical application were considered in the framework, especially the activity of coach. In general, problems addressed by balanced approach usually have practical applications. Thus, the need to provide both theory and recommendations for practical use seem to be universal to several cases.

\section{Patterns of Balanced Solutions}

The universal theory of balanced approaches can provide patterns of relationships between aspects which have their background in different approaches. The assumption is that a few background approaches are valuable, i.e. these are not cases of selecting one with rejection of others, or replacing older technology with a newer one.

The following patterns are possible:

- Independent dimensions: background approaches constitute different dimensions of software process and one can work independently in any of the dimensions; the only question is about priorities,

- Dimensions with overlapping: background approaches constitute different dimensions of the process with some overlapping, thus some connection points should be defined; e.g. [12],

- Time-ordered balance: different background approaches prevail in different stages of software development process, e.g. intensive use of creativity techniques during the analysis of innovative products and methodological software development in the following phases [13],

- Core approach with elements of other approaches: selection of the core background approach with incorporation of elements of other approaches taking into account a given criterion, e.g. balance between agile and disciplined software development with risk management [14],

- Process innovation: incorporation of novel approaches into existing process, e.g. experiments with gamification approaches when keeping application of best practice of software development process,

- Application dependent on circumstances: when several background approaches have different area of application or a different context of discovery, the decision can be made on the basis of analysis of the circumstances of the problem at hand and the fundamentals of the background approaches.

\section{Other Components of the Balanced Approach}

A logical consequence of the discovery that "it depends on several factors" is the question "what are these factors?" In search of them, one can use typical characteristics of software projects, such as type of product under development, complexity of software project, culture of company, stakeholders, team experience, main risks, legal and formal requirements, etc.

Another interesting question is whether we can use knowledge from other disciplines in order to avoid developing this theory from scratch in situation when several research results could be used by analogy or by knowledge transfer. What are these disciplines? What is specifics of their application? Innovation management seems to be a good source of knowledge on innovations in industrial context. Areas of multi-dimensional analysis and optimization can support increase of the level of methodological precision. Research results of empirical software engineering can deliver several interesting finding regarding the performance of software engineering processes in diversified situations. Identification of other disciplines acquiring insights from them is the task for further studies.

\section{CONCLUSIONS AND FURTHER WORK}

This paper presents work in progress and, as such, it generates more questions than it can answer. The addressed problems seem to be universal. If proper solutions are found, they can facilitate dealing with several situations of balancing different approaches in practice.

Regarding the first goal, this paper has presented the balanced approach to individual program of professional development for business analysts. The result is the framework which includes self-assessment of talents and competencies in confrontation with job requirements and methodologies. It should be performed iteratively as the ASIS state changes and business analyst become more aware of their talents as well as barriers in professional development. Business analysts might also face new challenges or they might aim at perfection in their professional development with use of efficiency measures for the competencies they work on as well as professional literature related to trends in business analysis.

This approach allows for conscious direction of professional development activities. In contrast to most of available professional trainings, its fundamental assumptions are individual programs and continues training. This is an important issue in times when everyone can expect several job changes, life-long learning is an increasing trend and personal responsibility for the professional career is reality.

Integration and balance appear to be beneficial to the professional development program. The approaches were based on complementary values. Talent-oriented approach focused on individual side of the professional development. Methodologies describe best practice of successful software development including placement in software development process and templates of work products. Competencies are like a link between techniques and personal talents. They 
allow business analysts to become aware of their talents and to make verified steps towards excellence.

There are several issues which should be added to the framework. For example, development of effective methods of training on skills related to specific business analyst behaviors are a challenge. Empirical studies from several cases of career development could provide validation of the proposed approach and many valuable insights.

Regarding the second goal, in this first step towards the universal theory of balanced approaches, several patterns of balance have been identified. Other components include: ways of integrating the background approaches before they can be balanced, consideration on both levels of theory and pragmatics, a set of factors, on which a pattern and/or decision depends. The factors include (but are not limited to) level of advancement in performing balanced activities, characteristics of software projects, comparison of the context of discovery and the context of application of a given approach. It is expected that knowledge from several disciplines can be applied by analogy or by knowledge transfer, but the complete list of disciplines and related knowledge transfers awaits further work.

\section{REFERENCES}

[1] Candle J., Paul D., Turner P., Business Analysis Techniques, British Informatics Society (2010)

[2] International Institute of Business Analysis: A Guide to the Business Analysis Body of Knowledge, version 3 (2015)

[3] Project Management Institute: Business Analysis for Practitioners: a Practice Guide (2015)
[4] Carkenord B.: Seven Steps to Mastering Business Analysis, B2T Training (2009)

[5] Brandenburg L., How to Start a Business Analyst Career. www.bridging-the-gap.com (2010)

[6] Madeiros dos Santos P.S, and Travassos G.H., Action Research Use in Software Engineering: an Initial Survey, In: Proceedings of the Third International Symposium on Empirical Software Engineering and Measurement, ESEM 2009 (2009), DOI: 10.1145/1671248.1671296

[7] Jacobson I., Ericsson M, Jacobson A.: The Object Adventure: Business Process Re-Engineering With Object Technology, Addison Wesley (1994)

[8] Jacobson I., Booch G., Rumbaugh J.: The Unified SOFTWARE DEVELOPMENT PROCESS, Addison Wesley (1999)

[9] IBM Rational Unified Process Specification, version 7.0.1, 2006, www.ibm.com.

[10] Buckingham M., StandOut: The Groundbreaking New Strengths Assessment from the Leader of the Strengths Revolution, Thomas Nelson (2011)

[11] Moczydłowska J.M., Kowalewski K., Nowe koncepcje zarzqdzania ludźmi (Novel concepts in HR Management), Difin (2014)

[12] Ferre X., Integration of Usability Techniques into the Software Development Process, In: Proceedings of ICSE 2003 Workshop on Bridging the Gaps Between Software Engineering and Human-Computer Interaction (2003)

[13] Bobkowska A., Balance Between Creativity and Methodology in Software Projects, In: Proceedings of the Multimedia, Interaction, Design and Innovation - MIDI '15, ACM DL (2015) DOI:10.1145/2814464.2814468

[14] Boehm B., Turner R., Balancing Agility and Discipline. A Guide for Perplexed, Addison-Wesley (2003) 